\title{
GEOMORPHOLOGICAL AND BATHYMETRIC RESEARCH ON LAKES ZERELIA OF ALMYROS (CENTRAL GREECE)
}

\author{
Gaitanopoulos A. ${ }^{1}$, Albanakis K. ${ }^{1}$ and Vouvalidis K. ${ }^{1}$ \\ ${ }^{1}$ Aristotle University of Thessaloniki, Department of Geology, 54124, Thessaloniki, Greece, \\ alexgaitanopoulos@gmail.com,albanaki@geo.auth.gr,vouval@geo.auth.gr
}

\begin{abstract}
The area of interest is located close to Almyros city, at the prefecture of Magnesia (Central Greece), where the twin lakes Zerelia are situated. The origin of these twin lakes is not clear, however, many hypotheses have been proposed over the years. A lack of large-scale mapping in the surrounding area and a high resolution spatial depiction of the topography, hinders the extraction of conclusions on the twin lakes' origin. Also, previous studies have focused on surficial evidence to support hypotheses, rather than investigating the geometric characteristics and the spatial lay-out of the twin lakes. Filling this gap, measurements of depth via sonar in Zerelia lakes were performed. The bathymetric data along with the digitized, high-resolution topographic data of the surrounding terrain were imported in a Geographic Information System (GIS) environment. The area was depicted with high accuracy through DEMs and conclusions for the landscape were extracted. The above analysis contributed towards an appreciation of the intense interplay between erosional and tectonic processes in the area and deemed drainage antecedence an important element that needs to be accounted for, in any interpretation of the origin of the twin lakes Zerelia.
\end{abstract}

Keywords: Xirias River, GIS, Digital Elevation Model (DEM), Drainage network, Bathymetry maps.

\section{Пєрí $\eta \Psi \psi \eta$}

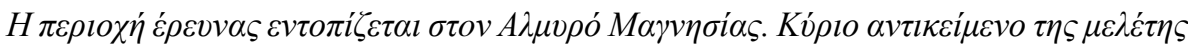

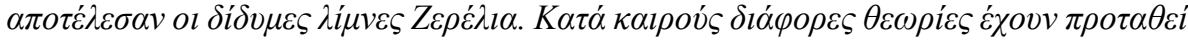

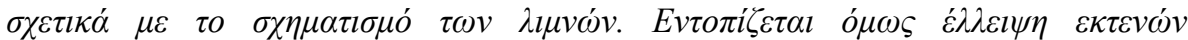

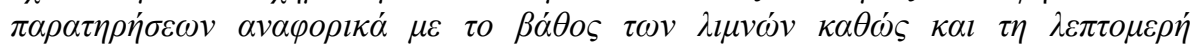

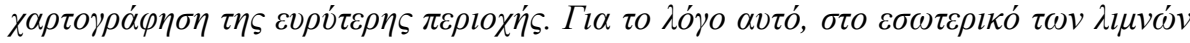

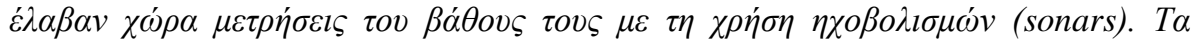

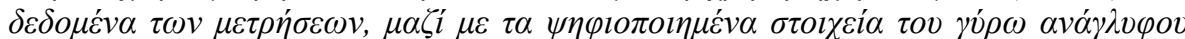

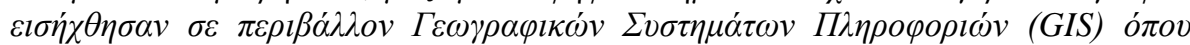

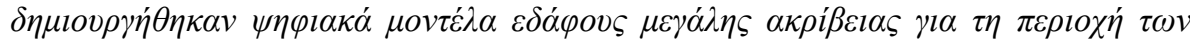

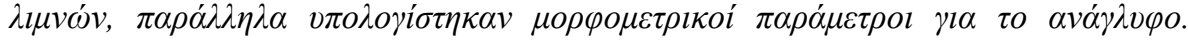

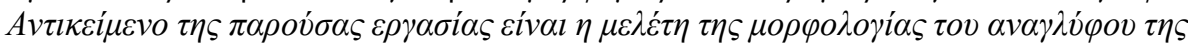

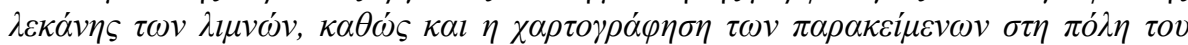

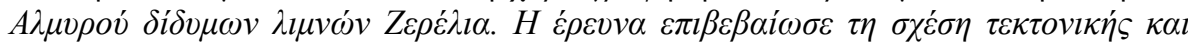

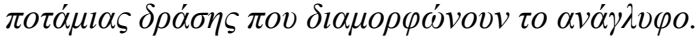

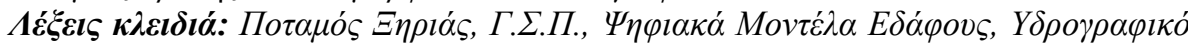

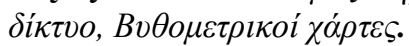




\section{Introduction}

The twin lakes Zerelia are situated approximately $5 \mathrm{~km} \mathrm{SW}$ of the town of Almyros, in the tectonically active landscape of central Greece. They appear to be very distinct geomorphic features which haven't been studied in detail (Figure 1). Preliminary inferences about the twin lakes' origin were made by Marinos (1963), while studying the Quaternary volcanic activity of Pagasitikos gulf, favoring an embryonic maar-type volcano origin. In later years, Galanakis (1999), while studying the neotectonics and landscape evolution of the broader Almyros basin area, concluded that fault action associated with karstic cavity collapse, played a decisive role in the creation of the lakes. The most recent research in the area, conducted by Lagios and his team, involved lithological sampling and geophysical surveys (Lagios et al., 2010). They favor a meteorite impact origin, involving two 10-30m meteorite fragments that disrupted the landscape during Holocene times.

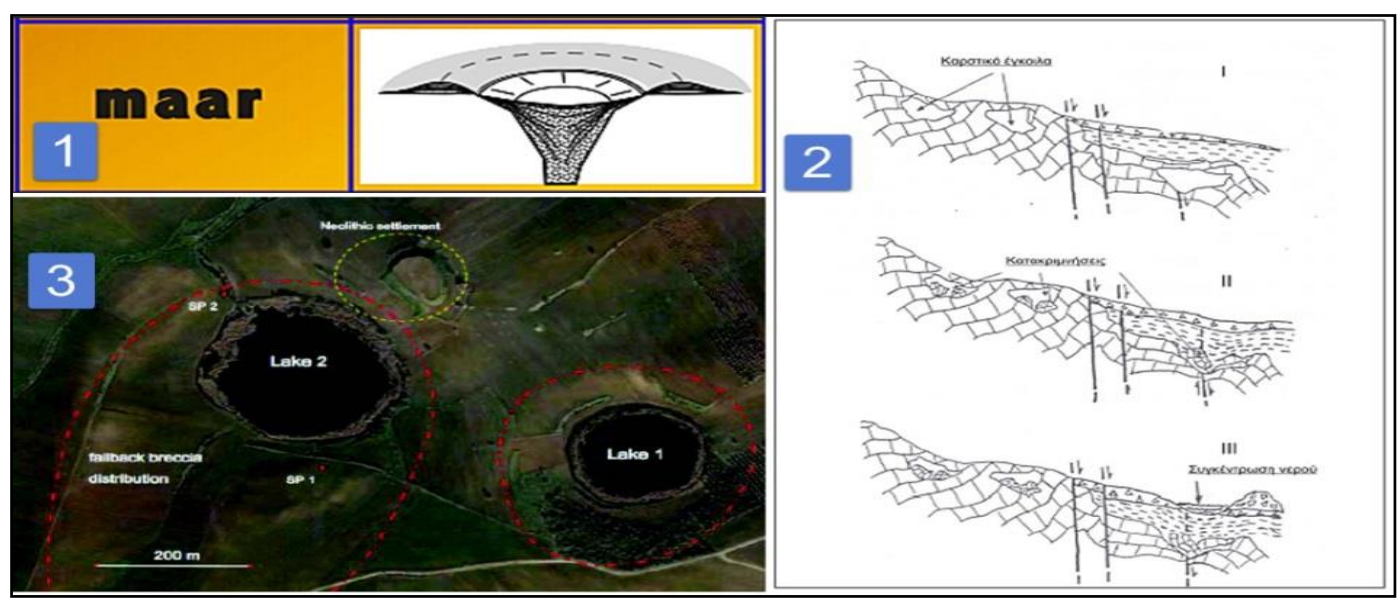

Figure 1 - Proposed models of origin on the twin lakes Zerelia, according to 1) Marinos (1963), 2) Galanakis (1999) and 3) Lagios et al. (2010).

Nonetheless, the detailed bathymetry of the lakes, which incidentally have never dried according to the locals, except as a result of an earthquake in 1980, has never been the subject of research. The papers contribution involves the acquisition of bathymetric data for the twin lakes Zerelia, along with the high-resolution depiction of the surrounding terrain, so as to place geomorphic constraints on any potential model on the origin of the lakes.

\section{Location and physiography of the study area}

The Zerelia twin lakes are located in central Greece at the prefecture of Magnesia, about $5 \mathrm{~km} \mathrm{SW}$ from the town of Almyros and nearly 2,5 km from Euxeinoupoli's Municipal department. The lakes are situated at an altitude of $130 \mathrm{~m}$, close to Mt. Othris northern foothills (Figure 2). The bigger, western lake, occupies an area of $44.000 \mathrm{~m}^{2}$ with a perimeter of $754 \mathrm{~m}, 10 \mathrm{~m}$ maximum depth and diameter of about $240 \mathrm{~m}$. The smaller, eastern lake occupies an area of $26.000 \mathrm{~m}^{2}$, has a perimeter of $600 \mathrm{~m}$, a maximum depth of about $8 \mathrm{~m}$ and a $160 \mathrm{~m}$ diameter. Both lakes' size attributes depend on the seasonal precipitation patterns and the irrigation conditions. Their altitudinal difference is estimated at around $4 \mathrm{~m}$ and the smaller lake appears on a lower altitude. The region is generally characterized by the typical continental climate of Thessaly, gradually transitioning into Mediterranean towards the east, bordering the Bay of Almyros, and exhibits hot and dry summers and mild and wet winters. Field evidence indicated that the lakes are developed on Pliocene marls which are impermeable (Galanakis, 1999). A broad alluvial plain, made up of red-brown marls, gravels and related Quaternary deposits, surrounds the lakes. Immediately adjacent to the lakes are remnants of a Neolithic settlement, probably occupied until the Late Bronze Age. The lakes' presence played an important and defining role to the early settlement's expansion (Reinders, 2004). 


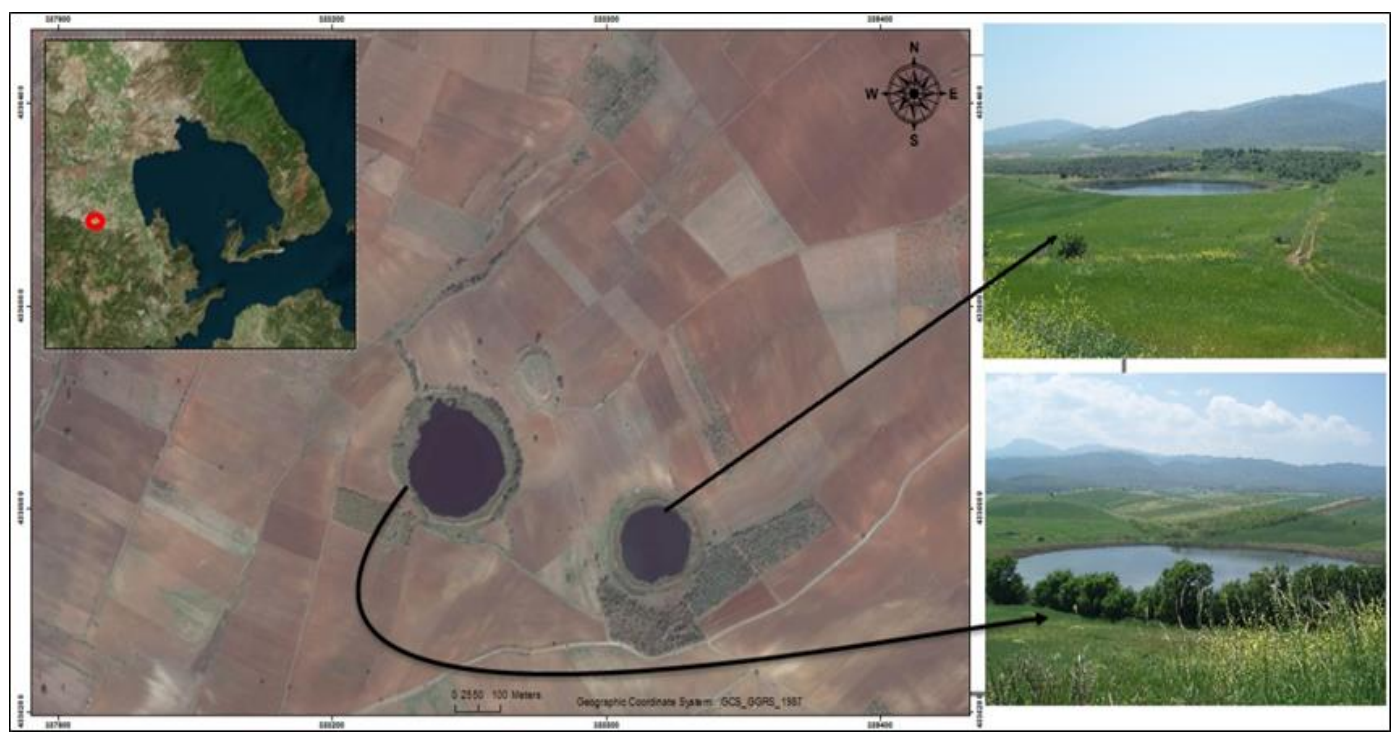

Figure 2 - Satellite image of the twin lakes and inset photographs. Top left side inset depicts the location of the study area (red circle) in the broader Magnesia prefecture area of central Greece.

\section{Materials - Methodology}

In order to develop a comprehensive look of the Zerelia Lakes Structure, the following data and software were used:

- Five topographical maps covering the study area of Almyros. Sheets: 5334/4, 5335/3, 5335/2, 5335/1, 5334/6 source: Hellenic Military Geographical Service (HMGS) scale 1:5,000. In this particular case 125 contours been digitized (contour interval $2 \mathrm{~m}$ ).

- Bathymetry measurements using GPS apparatus: Garmin® GPSMAP® 276C.

- Software MapSource 6.16.3 to optimize bathymetry's points.

- GIS software: ArcGIS 10.1.

Topographic maps were georeferenced with ArcGIS 10.1 to the EGSA 87/GGRS87 datum. Along with the contours, 104 peaks of the study area were digitized (Figure 3). Bathymetric measurements were subjected to necessary correlations and corrections, in order to end up with an acceptable bathymetric model. Overall, 400 point measurements were taken in the small lake. Additionally, more than 80 point measurements were made in the large lake. 


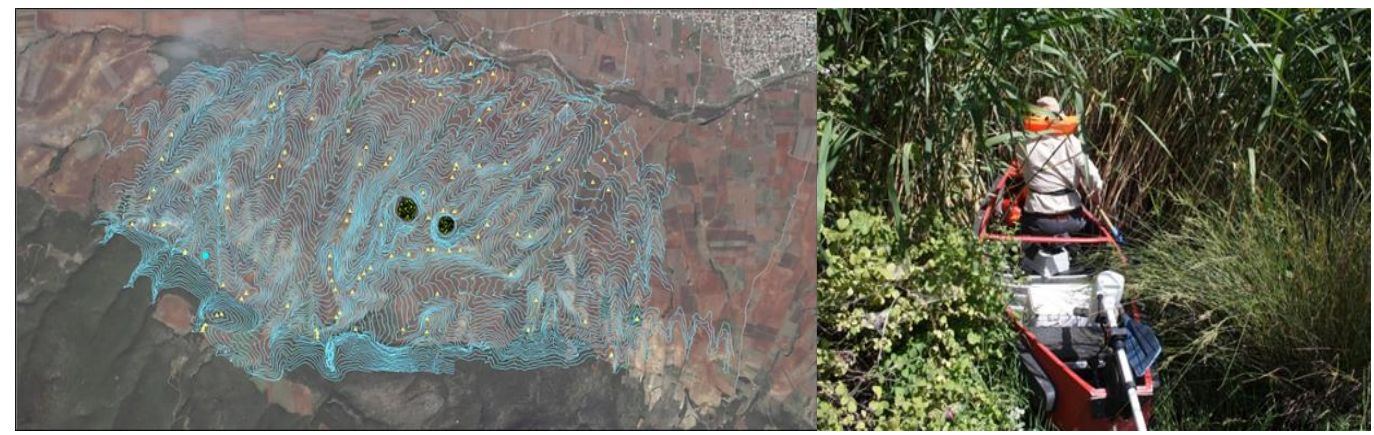

Figure 3 - Digitalized data used for terrain maps (left), entrance to small lake with canoe for measure depths (right).

\section{Thematic Maps}

The first map which was created through ArcGIS 10.1 Spatial analyst tools was the Digital Elevation Model (DEM) of the study area (Figure 4). Specifically, the DEM's area is located in the northern part of Mt.Othris foothills, underlain by a bedrock of Alpine-age formations (marls, limestones) and a cover of alluvial deposits (Galanakis, 1999). The altitudinal distribution ranges from $266 \mathrm{~m}$ to $79 \mathrm{~m}$, based on the constructed DEM. This relief is indicative of the magnitude of stream incision into previous alluvium due to vertical, fault-induced movements. All the above findings are clearly depicted on the terrain, on which small gorges are featured at the foothills bordering the Almyros basin. Lakes Zerelia are situated at an elevation of $130 \mathrm{~m}$, at the transition zone between the foothill and basin terrain.

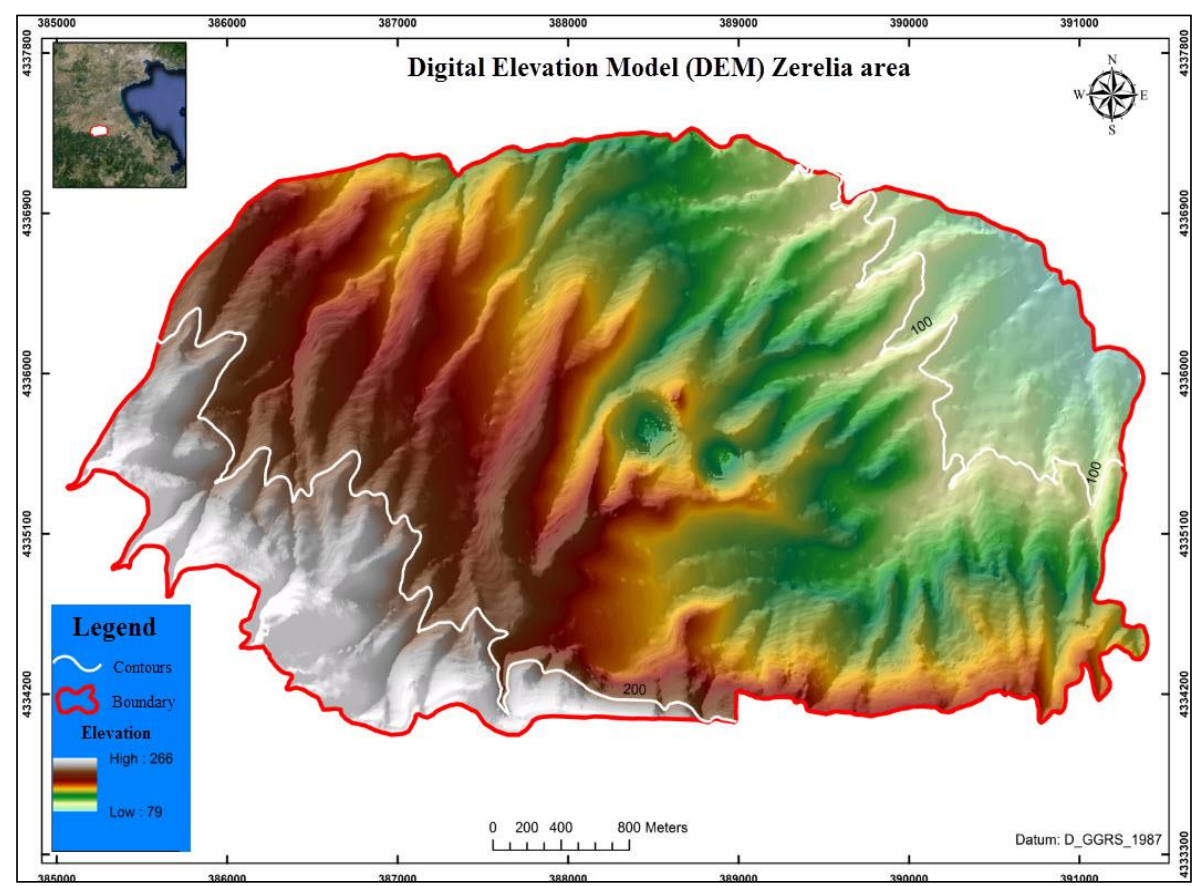

Figure 4 - Elevation map of the lake Zerelia surrounding terrain.

A slope map was also created, where slope values were classified according to the Demek classification (Demek, 1972). Estimation of the area percentage of each value range is presented (Table 1). 
Table 1 - Area of slope ranges in the lakes Zerelia surrounding terrain.

\begin{tabular}{|l|l|l|}
\hline Slope range & Land area in $\mathbf{k m}^{2}$ & Area percentage (\%) \\
\hline $0^{0}-2^{0}$ & 2,88 & 18 \\
\hline $2^{0}-5^{0}$ & 7,2 & 45 \\
\hline $5^{0}-15^{0}$ & 5,44 & 34 \\
\hline $15^{0}-35^{0}$ & 0,368 & 2,3 \\
\hline $35^{0}-55^{0}$ & 0,064 & 0,4 \\
\hline$>55^{\circ}$ & 0,048 & 0,3 \\
\hline & Sum:16km & 100 \\
\cline { 2 - 3 } & \multicolumn{2}{|l}{} \\
\cline { 2 - 3 } & \multicolumn{2}{|l}{}
\end{tabular}

Quantitative analysis of these values indicates the general lay-out of the region. Low slope values are prevailing, primarily under $5^{\mathrm{O}}$ as it is a flat terrain that has undergone a deposition of alluvial materials and its erosional products. Slopes of $5^{0}-15^{0}$ are mostly present at the foothills of the mountain where the altitude increases. Maximum slope values, although limited, appear around the lake walls. So, slopes greater than $55^{\circ}$ occur exclusively around the lakes (Figure 5). That revealed a steep terrain, which is not found elsewhere in the area.

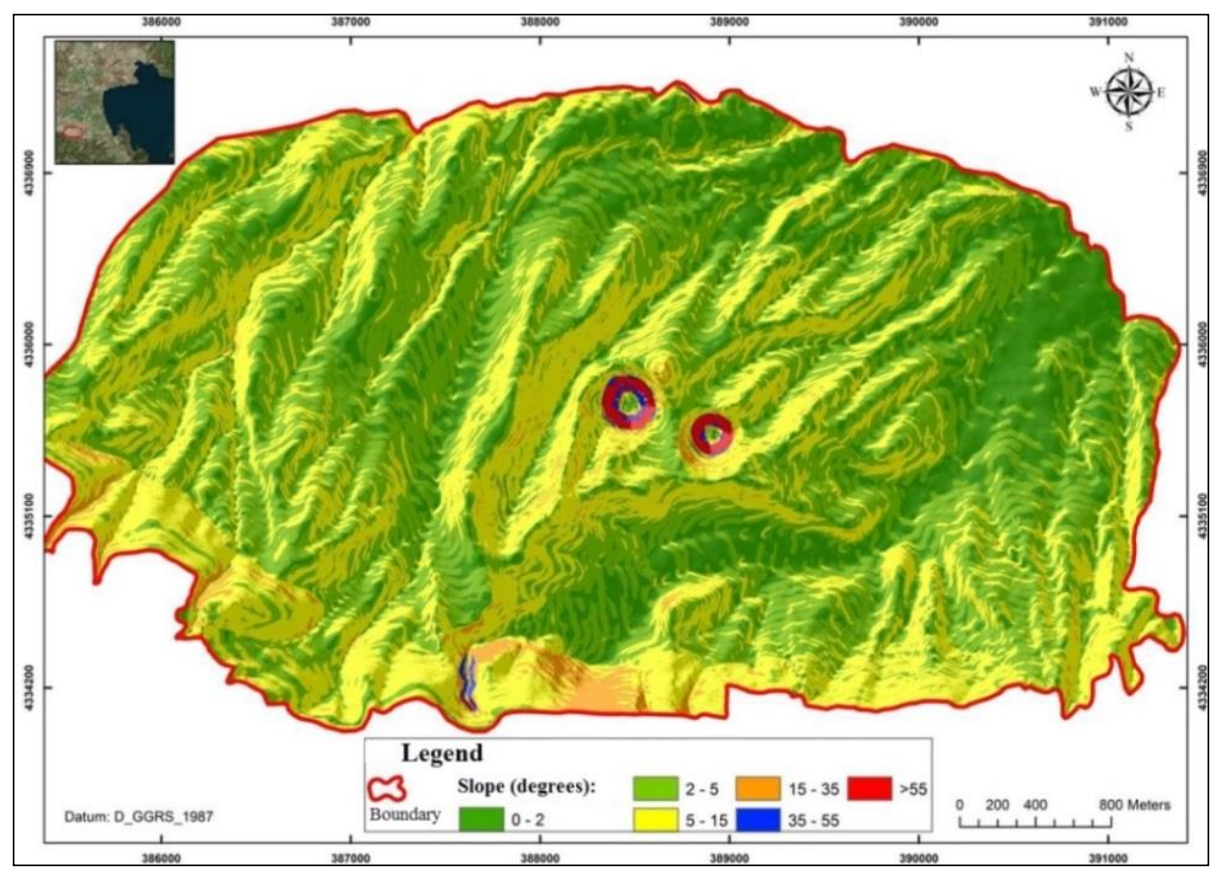

Figure 5 - Slope map of the lake Zerelia surrounding terrain.

Finally, morphological profiles were created in order to further analyze the terrain around the lakes (Figure 6). So, the first profile depicts the lakes' bowl-shaped cross-section and the altitude variations. The terrain becames significantly lower moving further into the lakes, with an average altitude of $20 \mathrm{~m}$. Additionally, the case of the West Lake is representative of how this change reflects on the topography. A drop from $140 \mathrm{~m}$ to $120 \mathrm{~m}$ is observed with the altitude beyond the bowl raising up again above $130 \mathrm{~m}$. The other two sections are related to each pond individually, giving an estimation of the width of each lake. The most important conclusion from these morphological sections is that 
East Lake's lower altitude fluctuates around $115 \mathrm{~m}$ in comparison to the western largest lake which is developed at an altitude of over $120 \mathrm{~m}$.

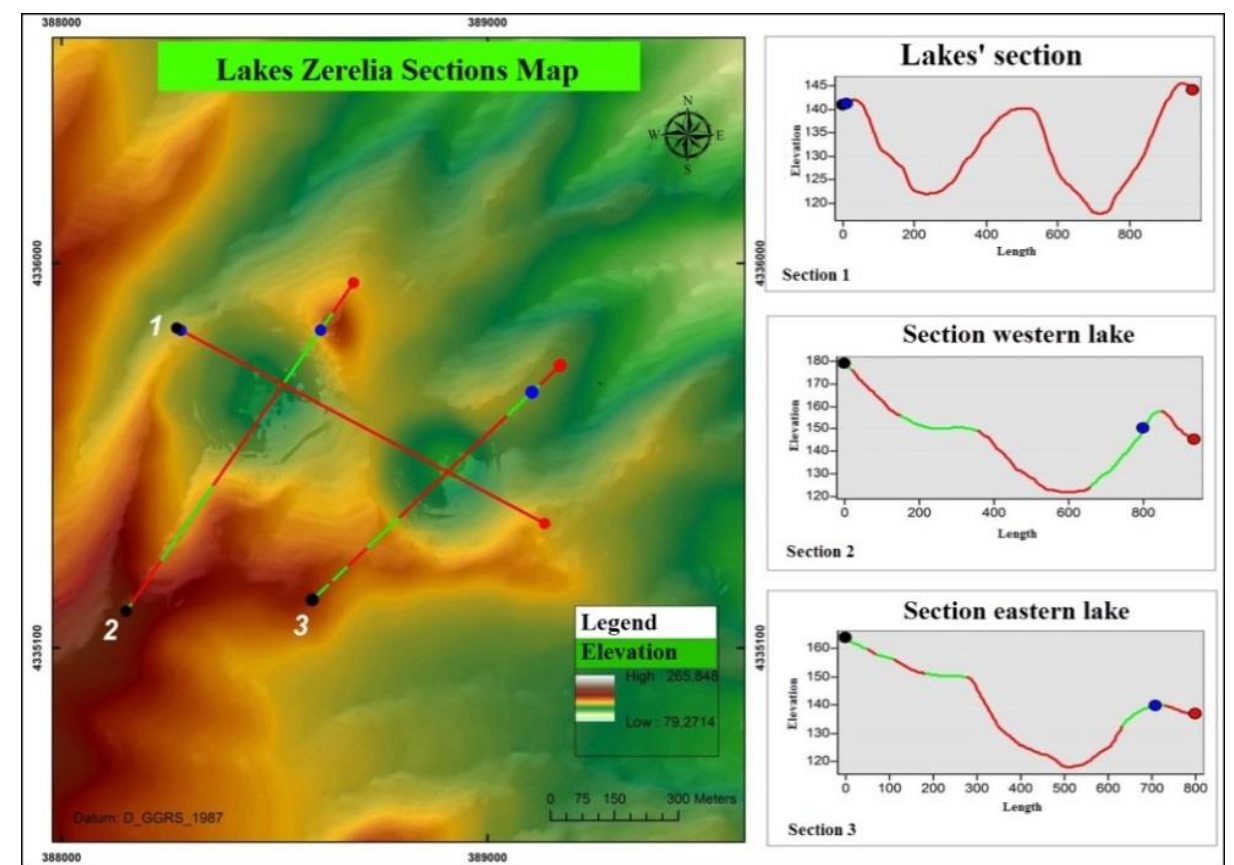

Figure 6 - Elevation map and corresponding topographic cross-sections of lakes Zerelia.

\subsection{Drainage network}

Through the identification and study of the drainage network, significant geomorphological remarks can be extracted (Keller et al., 2002). In this direction, drainage branches growing in this landscape are exported (Figure7). So it's directly observable that the drainage network takes the dendritic form only in the upper part of the basin where it actually it meets the foothill of the mountain. On the remaining part of the area and towards the Quaternary basin, the hydrographic network appears to have an elongated form with rapid development. Those elongated streams, as it is mentioned, appear to have rapid growth with intense erosive action and as a result of this, "V-shaped" valleys are formed during their motion. Moreover, downstream of the basin streams, a steep valley appears to be bending to the East as a consequence of the tectonic activity at the margins of the basin, while their orientation is affected significantly. The only area in which the described system is not observed is one of lakes Zerelia. Around the lakes' depressions no drainage related to that of the region is developed and those branches which probably grow by runoff, are driven into the lakes. Hence, it is demonstrated that the area of lakes appears to interrupt the development of the drainage network. Thereby we come to a conclusion that the lakes are subsequent to the drainage network. 


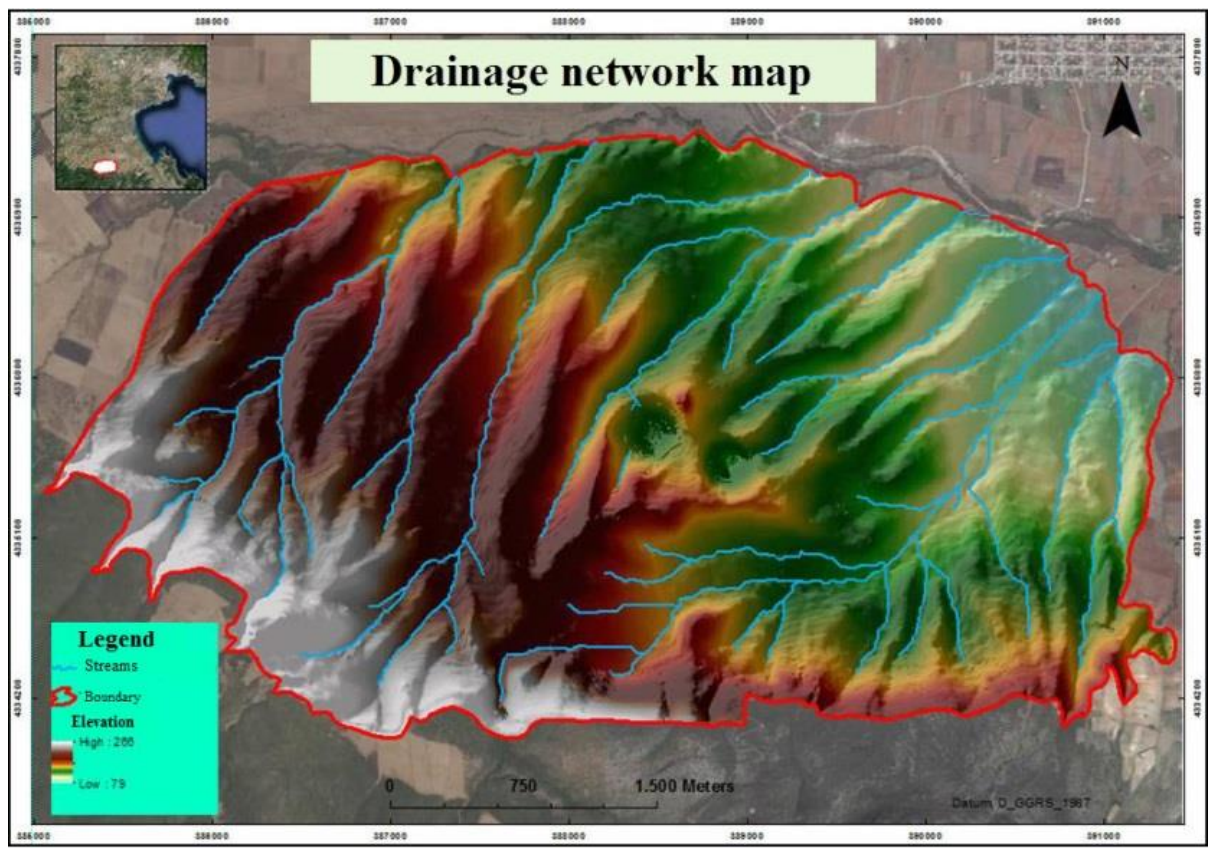

Figure 7 - Drainage network map of the surrounding lakes Zerelia terrain.

In addition, several longitudinal profiles of the streams draining the area where utilized to make observations that pertain to morphology (Figure 8). Longitudinal profiles reveal hydrographic branches with graded profiles and uniform development. Their riverbeds are in balance along with their development which is graded, no knickpoints appear and streams' orientation occur on a typical SSW-NNE direction. Lakes Zerelia don't seem to affect or modify the development of the drainage network, a fact that strengthens the scenario that lakes are subsequent and have been developed independently from the drainage network.

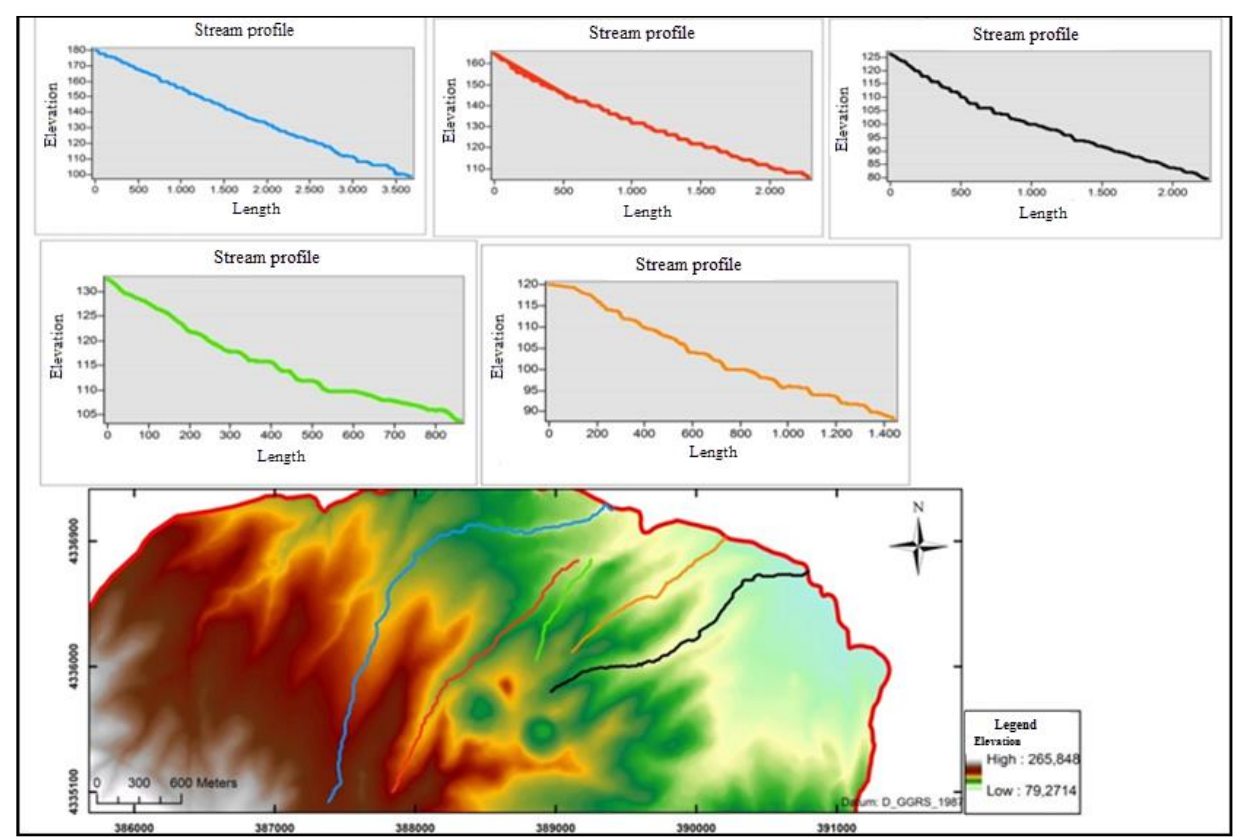

Figure 8 - Longitudinal profiles of streams draining the area surrounding the Zerelia lakes. 


\subsection{Bathymetry maps}

Bathymetry maps were created using the Kriging interpolation method, from sonar data acquired by research which was carried out in both lakes,. The first map depicts the bathymetric contours of the western lake Zerelia (Figure 9a). The contours' development indicates that depths in the lake are smoothly distributed from the periphery towards to the center. Possible local irregularities are likely but very difficult to track with the available means. Based on the map, the deeper parts of the lake appear almost in the center; relating to a smooth shift of the lakes' depth that forms a bowl shape. This is depicted in the morphological sections of the lake as well (Figure 9b).
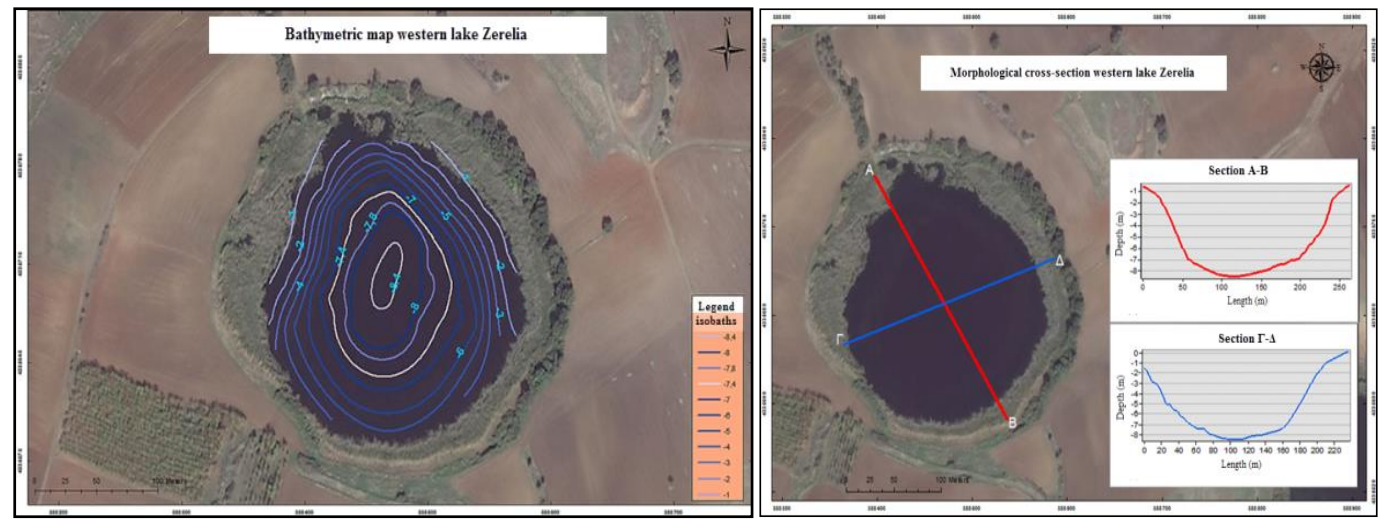

Figure 9 - a) Bathymetric map of the western lake Zerelia, b) superimposed on satellite image, and corresponding bathymetric cross-sections.

Morphology in the eastern, smaller lake is different; the range, the density and the greater reliability of measured points enable the creation of a more precise and detailed map of the lake. The spotted measurement points, after the necessary adjustments were around 300. So the following bathymetric map (Figure 10a) presents a different shape of the lake, and depicts with greater accuracy its bottom topography. An irregular distribution of depth in the lake is observed. The biggest changes occur deeper into the lake $(>6 \mathrm{~m})$ at its center, where the bottom does not appear as a smooth surface. It is also concluded that the bottom is extended compared to the total size of the lake; as isobaths of -7,0 $\mathrm{m}$ are widely distributed in the given space (Figure 10a). The walls of the lake present steeper slopes as the isobaths are denser and the depth appears to be increasing rapidly towards to the center of the lake; a fact that is also depicted by the morphological sections of the lake (Figure 10b).
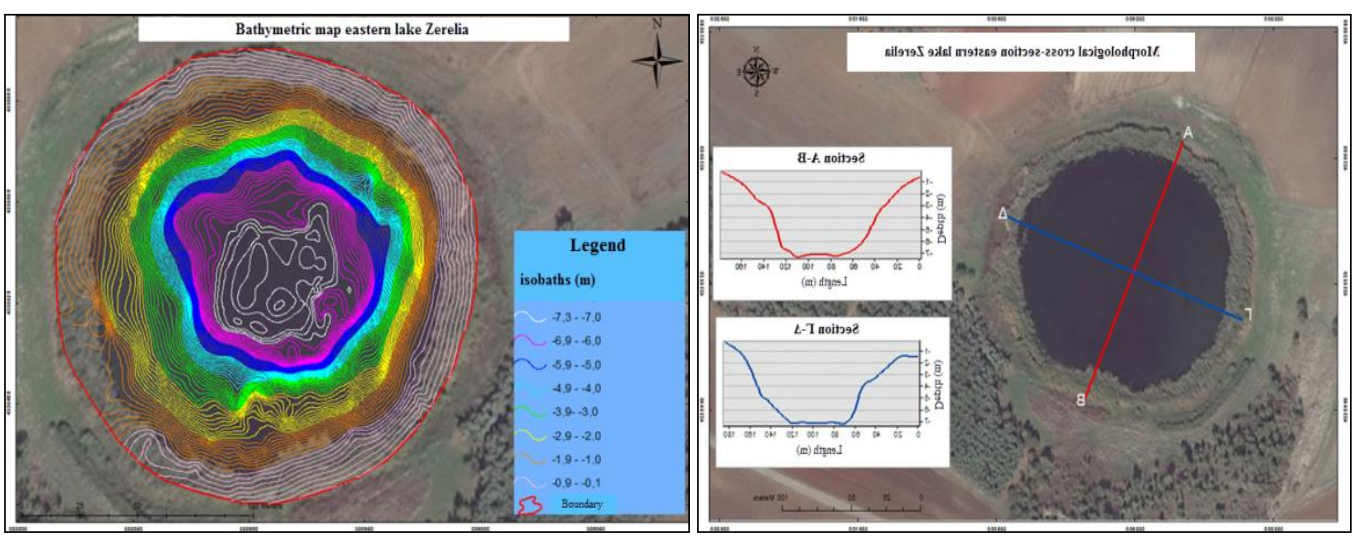

Figure 10 - a) Bathymetric map of the eastern lake Zerelia, b) superimposed on satellite image, and corresponding cross-sections. 


\section{Conclusions}

Through the digital mapping of the study area and the export of high accuracy Digital Elevation Models (DEMs) the morphological terrain in the lakes area was studied; along with the slope development, the orientation of the landscape and the development of the drainage network. The region of scope occurs across the southern margin of the Almyros basin, terrain's slopes are mainly smooth, particularly low slope values do prevail, primarily under $5^{\circ}$, as it is a flat terrain that has undergone a deposition of alluvial materials and its erosional products. Higher slope values occur at the foothills of the mountain where the altitude increases. Values greater than $55^{\circ}$ occur mainly around the lakes, a fact that reveals a steep terrain uncommon in another parts of the region. Studying the drainage network leaded to the following conclusions; the dendritic form of the drainage network appears only at the foothill of the mountain. Downstream, the hydrographic network appears to have an elongated form with rapid development. Denudation processes are intense forming "V-shaped valleys" while streams erode soft sediments. Riverbeds are in balance; no sing of tectonic intervention at streams' development and no knickpoint appear at their profiles. Although tectonic action does affect streams' orientation that only occurs at the margins of the basin where the branches arrive. Lakes Zerelias' depressions don't affect the development of the drainage network meaning that lakes are subsequent and have been developed independently of the drainage network. Zerelia lakes, which were formed in the transition zone between foothills and basin, are interrupting the aforesaid sequence of the terrain. Bathymetry maps produced, reveal that the maximum depth on the western lake is estimated at $9,5 \mathrm{~m}$, while on the eastern is 7,3 m. Morphological sections of each lake were created and sections prove that the slopes of the walls on the eastern small Zerelia is steeper with an extensive lake floor. Walls on the western lake are smoother and seem to have a typical bowl shape. All in all, lakes' depressions appear to have steep walls with flat bottoms and their creation is not related with the surrounding terrain.

\section{References}

Demek, J., 1972. Manual of detailed geomorphological mapping, Academia, Prague, 344 pp.

Galanakis, D., 1999. Neotectonics structure and stratigraphy of Neogene-Quaternary sediments of the basin of Almyros-Pagasitikos Pelion Trikeri Channel and Maliakos, PhD Thesis (in Greek).

Keller, E.A. and Pinter, D.J., 2002. Active Tectonics, Earthquakes, Uplift and Landscape. Second edition, Prentice-Hall, Inc., New Jersey, 1-338 pp.

Lagios, E., Dietrich, V., Gartzos, E., et al., 2010. Mineralogical and geophysical investigations on the twin-meteorite impact craters in Thessaly (central Greece).

Marinos, G., 1963. About two embryonic volcanoes Maare type, at Almyros Thessaly (in Greek). Reinders, H.R., 2004. Prehistoric Sites at the Almyros and Sourpi Plains (Thessaly Greece). 